\title{
Skeletal Manifestations in Acute Lymphoblastic Leukaemia
}

\author{
MAHMUDA BEGUM ${ }^{1}$, L. E. FATMI ${ }^{2}$, KHANDAKER TAREQUL ISLAM ${ }^{3}$ ' SYEDA MEHNAZ ${ }^{4}$, S.M. \\ SHAMSUL HUDA ${ }^{5}$, FARHANA RAHMAN ${ }^{6}$
}

\begin{abstract}
:
Background: Skeletal manifestations associated with ALL in children are common findings with a high prevalence (11.6 to 50\%). The most common skeletal manifestations are bone pain, arthritis, failure to use an extremity as well as other complaints mimicking orthopedic condition such as osteomyelitis. The objective of this study is to determine the rate of skeletal manifestations commonly present in $A L L$ to reduce mortality and morbidity.

Methods: This cross-sectional study was carried out in the department of Pediatrics in Dhaka medical college Hospital, BSMMU and Dhaka Shishu (Children) Hospital between January 2010 to July 2010. Total Fifty patients of ALL were Selected consecutively from the study population. At first, we assessed skeletal manifestations like bone pain, arthritis, radiological findings present or not in ALL. Then specify the rate of bone pain, arthritis, radiological findings of ALL patients.

Results: After six months 35 patients were present with skeletal manifestations. Among them 20 patients, presented with bone pain, 10 patients presented with arthritis and 5 patients presented with radiological manifestations. Out of 5 patients 3 patients had soft tissue swelling 1 patient had periarticular osteoporosis and 1 patient had joint effusion in $x$-ray findings.
\end{abstract}

Conclusion: Skeletal manifestations may be the only presentation in ALL.

Key words: Acute Lymphoblastic Leukaemia, Skeletal manifestations.

\section{Introduction}

Acute Lymphoblastic Leukemia (ALL) is a malignant (Clonal) disease of the bone marrow in which early lymphoid precursors proliferate and replace the normal hematopoietic cells of the marrow. ${ }^{1,2}$ It constitute $25-30 \%$ of all childhood cancer. ${ }^{3}$

Skeletal manifestations associated with Acute lymphoblastic leukemia (ALL) in children are common findings with a prevalence estimated between 11.6 and $50 \% .4,5$ The most common skeletal manifestations are localized or diffuse bone pain,

1. Junior Consultant Pediatrics, Keranigong Upazilla Health Complex, Dhaka.

2. Professor and Head of the department of Haematology and Oncology, Holy family Hospital, Dhaka.

3. Junior Consultant, Department of Pediatrics, Shaheed Suhrawardy Medical Hospital, Dhaka.

4. Medical officer, Kurmitola General Hospital, Dhaka.

5. Consultant, Department of Paediatric Surgery, BSMMU, Dhaka.

6. Assistant Professor, Delta Medical College, Dhaka.

Correspondence: Dr Mahmuda Begum, Junior Consultant of Paediatrics, Upazilla Health Complex, Keraniganj, Dhaka. Mob: 01843893454 Email: mahmudabegum142@gmail.com.

Received: 12-03-2018 arthritis, failure to use an extremity, as well as other complaints mimicking orthopedic conditions such as osteomyelitis. In addition, the affected individuals present an increased risk for fracture. ${ }^{6,7}$

During the course of the disease between 70 and $90 \%$ patients with ALL are reported to show abnormal skeletal findings on radiographs such as osteopenia, cortical lucencies, metaphyseal bands on combinations thereof pathological changes in bone with subsequent skeletal morbidity are caused by leukemic cells as well as by the chemo therapeutic agents and glucocorticoids used in leukemia treatment. $^{8-10}$

Arthritis can occur at any time during the course of acute leukemia. It may lead to delay in diagnosis and delay in therapy, it is associated with poor prognosis and the most common clinical presentation of leukemic arthritis is additive or migratory asymmetrical oligo articular large joint arthritis. The joint most commonly involved are the knee, followed by the ankle, wrist, elbow, shoulder and hip. Onset 
of arthritis may be sudden or insidious and parallel the course of acute leukemia.$^{11-16}$

Children with leukemia may first present with skeletal manifestations mimicking JIA and often normal hematological variable. The correct diagnosis may be often delayed because evaluation focuses on the arthritis with sometimes treatment with steroids started early, which delay diagnosis further and reduces the subsequent response to chemotherapy. MJ MYRRY ,Specialist registrar pediatric oncology report a case initially diagnosed as JIA in which ALL become apparent six months after presentation and after treatment with steroid and methotrexate. This case emphasized the importance of early bone marrow examination if there are any atypical features of JIA and certainly before starting steroids or cytotoxic agents. ${ }^{17}$

\section{Materials and Methods}

This cross-sectional study was conducted in the Department of Pediatric Hematology and oncology in $\mathrm{DMCH}, \mathrm{BSMMU}$ and Dhaka Shishu (Children) Hospital from January 2010 to July 2010.Total 50 diagnosed patients of ALL up to 18 years of age attending indoor of Hematology and oncology department of above-mentioned Hospitals were selected consecutively from the study population. Various Skeletal manifestations like bone pain, Arthritis, Radiological manifestations were categorized in proportion. Further Radiological manifestations like soft tissue swelling, periarticular osteoporosis and joint effusion also categorized in proportion.

Data were processed and analyzed using computer software (SPSS) version 17. Presentation was done by tables and graphs. The cut-off value $<0.05$ considered as significant.

\section{Results}

In this study total 50 patients of ALL were included from indoor of Hematology and oncology Department. Immediately after admission history about bone pain, Arthritis were taken. Then proportion of patients having bone pain/arthritis was calculated. Then $x-$ ray of the affected joints was done. Then proportion of radiological findings like soft tissue swelling, periarticular osteoporosis and joint effusion were calculated. The results are shown in different tables and graphs.
Table-I

Age variation at the time of presentation of study group

\begin{tabular}{lcc}
\hline Age in years & Number of patients & Percentage \\
\hline $1-5$ & 20 & $40 \%$ \\
$6-10$ & 20 & $40 \%$ \\
$11-14$ & 10 & $20 \%$ \\
\hline
\end{tabular}

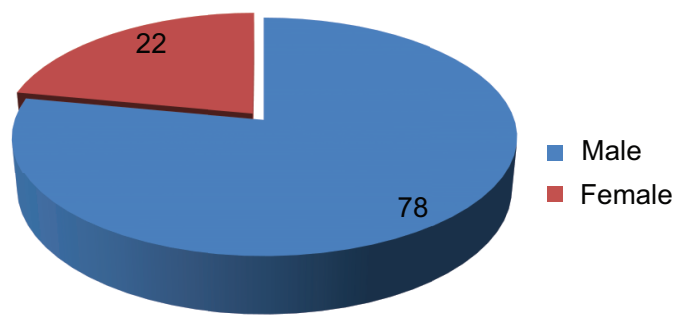

Fig-1: Sex distribution of patients.

In this series male children appeared to be affected more than the female, male-female ratio 3.54:1

Table-II

Rate of skeletal manifestations in study group

\begin{tabular}{lcc}
\hline Skeletal manifestations & $\begin{array}{c}\text { Number } \\
\text { of patients }\end{array}$ & Percentage \\
\hline Present & 35 & $70 \%$ \\
Absent & 15 & $30 \%$ \\
\hline
\end{tabular}

Table-III

Rate of Bone pain in study group

\begin{tabular}{lcc}
\hline Bone pain & Number & Percentage \\
\hline Present & 20 & $40 \%$ \\
Absent & 15 & $30 \%$ \\
\hline
\end{tabular}

Table-IV

Rate of Arthritis in study group

\begin{tabular}{lcc}
\hline Radiological & Number & Percentage \\
\hline Present & 10 & $20 \%$ \\
Absent & 25 & $50 \%$ \\
\hline
\end{tabular}

Table-V

Rate of Radiological manifestations (Positive $x$-ray findings) in study group

\begin{tabular}{lcc}
\hline Radiological & Number & Percentage \\
\hline Present & 5 & $10 \%$ \\
Absent & 30 & $60 \%$ \\
\hline
\end{tabular}


Table-VI

Rate of various radiological manifestations in study group individually

\begin{tabular}{lcc}
\hline Arthritis & Number & Percentage \\
Soft tissue swelling & 3 & $6 \%$ \\
Periarticular osteoporosis & 1 & $2 \%$ \\
Effusion & 1 & $2 \%$ \\
Loss of articular cartilage & 0 & \\
Erosion & 0 & \\
\hline
\end{tabular}

\section{Discussion:}

This cross-sectional study has been carried out in Dhaka medical college Hospital, BSMMU and Dhaka Shishu Hospital and fifty patients were taken as sample volume. In this study at first we assessed the skeletal manifestations like bone pain or back pain ,arthritis or radiological findings present or not in diagnosed case of ALL. Then specify the rate of bone pain or arthritis or radiological findings of ALL patients. ${ }^{11-19}$ We found $40 \%$ ALL patients presented with bone pain, $20 \%$ patients with arthritis and $10 \%$ patients with radiological manifestations like soft tissue swelling ( $6 \%)$, periarticular osteoporosis $(2 \%)$ and effusion (2\%).

Ninna Brix et al. conducted a retrospective study on 286 ALL patients to see the rate of arthritis present in ALL patients. They showed that $18.5 \%$ children with ALL presented with arthritis which is similar to the result of our study. ${ }^{18}$

Riccardo Sinigaglia et al. conducted a retrospective review on 22 ALL patients to see the various skeletal manifestations present in ALL. They found 35\% patients presented with bone pain, soft tissue swelling $10.6 \%$, joint effusion $5.7 \%$. This result is almost similar to our study. ${ }^{19}$

Carria Maria et al. conducted a study on 61 diagnosed case of Acute leukemia and they found $62 \%$ patients presented with skeletal pain, $8 \%$ with arthritis which is nearer to the result of our study ${ }^{20}$

Previously several studies were conducted by Basma Afaris, H Mulder, Maktoom Shahnazi et al. found almost $70 \%$ of patients ALL presented with bone pain. They also found periarticular osteoporosis and joint effusion which are similar to our study. ${ }^{21}$

\section{Limitations of the study:}

Study was conducted on small sample size and no control patients were taken in this study.

\section{Conclusion:}

Skeletal manifestations like bone pain, arthritis as well as various radiological manifestations like soft tissue swelling, joint effusion and periarticular osteoporosis are common in ALL.

\section{References}

1. D Astous J, Corrigon M, Wiley J. The musculoskeletal manifestations of acute lymphatic leukemia in childhood. Orthop Trans 1984; 8:460.

2. Gallagher DJ, Phillips DJ, Henrich SD. Orthopedic manifestations of acute pediatric leukemia. Orthop Clin North Am 1996; 27 :635644.

3. Lanzkowsky P. Manual of Paediatric Haematology and Oncology, Churchill Livingstone, $2^{\text {nd }}$ edition $1995 ; 1: 181-87$.

4. Tuten HR, Gabos PG, kumar SJ, Harter GD. The limping child: a manifestations of acute leukemia .J pediatr orthop 1998; 18:625-629.

5. Marsh WL Jr, Bylund DJ, H ealth VC, Anderson MJ. Osteo articular and pulmonary manifestations of acute leukemia. Case report and review of the literature. Cancer $1986 ; 57$ :385-390.

6. Rogalsky RJ, Black GB, Reed MH. Orthopedic manifestations of leukemia in children. J Bone joint surge Am 1986; 68 :494-501.

7. Silverstein MN, Kelly PJ. Leukemia with osteo articular symptoms and signs. Ann Int Med 1963 ;59 : 637-645.

8. Davies JH, Evans BAJ, Jenny MEM, Gregony JW. Skeletal morbidity in childhood acute lymphoblastic leukemia. Clin Endocrinol 2005; $63: 1-9$.

9. Chan KW. Acute lymphoblastic leukemia.Curr probl pediatr Adolesc Health care 2002 ; 32 :4049.

10. Mandel K Atkinson S, Barr RD Percharz P. Skeletal morbidity in childhood acute lymphoblastic leukemia.J Clin orcol 2004 ;22:1215-1221.

11. Thomas LB, Fonkner CE, Frei E 31-d, Besse BE Jr, Stabena UJR. The Skeletal lesions of acute leukemia, Cancer 1961; 14 :608-21. 
12. Silverstein MN, Kelly PJ. Leukemia with osteoarticular symptoms and signs, Ann Intern Med $1963 ; 59: 637-45$.

13. GURH, Koren V, Ehrenfeld M, Ben-Basalt I, Sidi Y. Rheumatic Manifestations preceding adult acute leukemia: Characteristics and implication in course and prognosis, Acute Haematol 1999 ;101:1-6.

14. Bradlow A, Barton C. Arthritic presentation of childhood leukemia. Post grade Med J 1991 ;67: 152-64.

15. Reyes ZT, Kardos G, K ajtar P, Schuler D. The adverse effect of prolong prednisolone pretreatment in children with ALL. Cancer 1985; 55:1637-40.

16. Kushner DC, Weinstein HJ, Kirk patrick JA. The radiological diagnosis of leukemia and lymphoma in children. Semin Roentgenol 1980; $15: 316-34$.

17. Parker BR, Marglin S, Castellino RA. Skeletal manifestations of leukemia, Hodgkin disease, and Non-Hodgkin lymphoma. Semin Reontgerol 1980; 15:302- 15.

18. Brix $\mathrm{N}$ et al. Arthritis as presenting manifestations of ALL in children. Arch Dis child 2015; 100:821-825.

19. Riccardo Sinigaglia et al. Musculoskeletal manifestations in pediatric ALL. Journal of pediatric orthopaedics 2008 ;28(1):20-28.

20. Maria $\mathrm{C}$ et al. Musculoskeletal manifestations as the onset of Acute leukemias in childhood. J pediatr $2002 ; 78(6): 481-4$;

21. H Mulder. Musculoskeletal manifestations in children with ALL. Journal of pediatrics 2007;27:1-4. 